\title{
Subtle changes in the flavour and texture of a drink enhance expectations of satiety
}

\author{
Keri McCrickerd ${ }^{1 *}$, Lucy Chambers ${ }^{1}$, Jeffrey M Brunstrom² ${ }^{2}$ and Martin R Yeomans ${ }^{1}$
}

\begin{abstract}
Background: The consumption of liquid calories has been implicated in the development of obesity and weight gain. Energy-containing drinks are often reported to have a weak satiety value: one explanation for this is that because of their fluid texture they are not expected to have much nutritional value. It is important to consider what features of these drinks can be manipulated to enhance their expected satiety value. Two studies investigated the perception of subtle changes in a drink's viscosity, and the extent to which thick texture and creamy flavour contribute to the generation of satiety expectations. Participants in the first study rated the sensory characteristics of 16 fruit yogurt drinks of increasing viscosity. In study two, a new set of participants evaluated eight versions of the fruit yogurt drink, which varied in thick texture, creamy flavour and energy content, for sensory and hedonic characteristics and satiety expectations.

Results: In study one, participants were able to perceive small changes in drink viscosity that were strongly related to the actual viscosity of the drinks. In study two, the thick versions of the drink were expected to be more filling and have a greater expected satiety value, independent of the drink's actual energy content. A creamy flavour enhanced the extent to which the drink was expected to be filling, but did not affect its expected satiety.

Conclusions: These results indicate that subtle manipulations of texture and creamy flavour can increase expectations that a fruit yogurt drink will be filling and suppress hunger, irrespective of the drink's energy content. A thicker texture enhanced expectations of satiety to a greater extent than a creamier flavour, and may be one way to improve the anticipated satiating value of energy-containing beverages.
\end{abstract}

Keywords: Beverage, Creamy flavour, Satiety expectations, Sensory characteristics, Viscosity

\section{Background}

In the UK, beverages account for approximately $18 \%$ of an adult's daily energy intake [1] and evidence that energy-yielding beverages have a weak satiety value suggests that the 'fluid calories' in our diet could be a quiet contributor to obesity and weight gain [2]. A variety of studies indicate that energy consumed in liquid form fails to suppress subjective appetite [3,4] or reduce subsequent food intake [5-7] to the same extent as equi-caloric solid food. However, other studies have reported no relationship between food form and its satiety value $[8,9]$, although a general criticism of studies in this field is that they often compare dissimilar foods (for example, calorie-matched cola against cookies) across

\footnotetext{
* Correspondence: k.mccrickerd@sussex.ac.uk

'School of Psychology, Pevensey Building, University of Sussex, Brighton BN1 $9 \mathrm{QH}$, UK

Full list of author information is available at the end of the article
}

a range of food contexts (for example, a beverage or a snack), and do not quantify differences in the cognitive and sensory evaluations of these foods $[10,11]$. Therefore, it is important to consider what it is about these features of energy-yielding liquids that limit their satiety value.

Because of their fluid nature, beverages require less oral processing time than semi-solid and solid caloric equivalents and as a result they are consumed fairly quickly, minimising oro-sensory exposure [12]. Although increasing oral processing time may not necessarily lead to a reduction in the amount of a food that is consumed [13], orosensory exposure is important for the development of satiety $[14,15]$ : the thought, sight, smell and taste of food trigger a cascade of anticipatory salivary and gastrointestinal responses, which improve the efficiency of nutrient processing and enhance the experience of satiety [16-19].

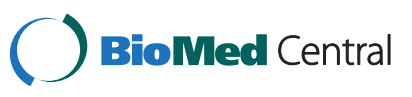


Oro-sensory exposure to food is thought to trigger anticipatory responses because animals, including humans, learn to associate the sensory characteristics of a food with its caloric value post-consumption [20-23], and these associations are likely to influence explicit expectations about the effect a food will have on appetite $[24,25]$, including how filling a food is likely to be (expected satiation) and the extent to which it will stave off hunger until the next meal (expected satiety): such expectations have been shown to influence appetitive satisfaction and portion size selection [26-28] and seem to be more strongly influenced by certain sensory characteristics. For example, a food is expected to be more filling when it is perceived to be heavier [29] or thicker in texture [30]. One explanation for the reported weak satiety value of beverages is that because of their fluid texture they are not expected to have much nutritional value $[2,11]$.

Studies indicate that 'thick' drinks suppress hunger to a greater extent than equi-caloric flavour matched 'thin' versions [31,32] and recent research suggests that the sensory characteristics of a beverage interact with its post-ingestive effects to influence satiety. Yeomans and Chambers [33] reported that a high-energy liquid preload suppressed intake at a later meal to a greater extent than a low-energy equivalent, but only when the beverage had a thick texture and a creamy flavour. Furthermore, when participants consumed the low-energy version with thick and creamy sensory characteristics they ate more at the test meal than after the low-energy version without the enhanced sensory context. The researchers argue that the thick and creamy sensory characteristics predicted the delivery of nutrients, generating expectations that these drinks would be filling, which acted to enhance the experience of satiety when energy had been consumed. Thus, when the sensory characteristics predicted nutrients that were not delivered (as with the low-energy version of the thick and creamy drink) the mismatch between the actual and expected nutrient delivery tended to result in rebound hunger.

According to the findings of Yeomans and Chambers [33], designing a high-energy drink to taste thick and creamy could be one way to increase its satiating capacity, but their results also suggest that designing a lowenergy drink to taste thick and creamy might actually increase subsequent appetite. Presumably, this is because a drink that tastes thick and creamy will increase expectations of satiety, regardless of its actual energy content, which would only be determined post-consumption. However, the extent to which the sensory characteristics of a drink influence expectations of satiety is not clear, and it is important to consider this if these expectations interact with the energy content of a drink postconsumption.
To characterise the influence of sensory cues on such expectations, we investigated the role of satiety-relevant texture and flavour cues in the generation of satiety expectations in high- and low-energy drinks. In study one, we assessed the extent to which participants were sensitive to small changes in drink texture and how sensory perceptions relate to the actual viscosity of a drink: it is important to clarify the scale of textural manipulations and how they actually translate to physical differences within a liquid product, in order to make it easier to compare textural differences of drinks across studies. In study two, we examined whether small variations in the thick texture and creamy flavour influence expectations of satiety, irrespective of the drink's actual energy content. We assessed the role of texture and flavour as independent sensory cues and together in a combined sensory context (thick and creamy) to see how the two interact.

\section{Results: study one}

Participants who were not sensory panellists tasted and rated 16 fruit yogurt drinks of varying thickness, manipulated by the addition of small quantities of tara gum ( 0.0 to $0.47 \mathrm{~g} / 100 \mathrm{~g}$ of the drink, increasing in $0.03 \mathrm{~g}$ increments across the 16 drinks). Rheological measurements were taken and participants rated how thick, creamy, fruity, sticky, sweet and sour each sample was $(0=$ not at all, $100=$ extremely $)$ on two non-consecutive days. Perceived thickness was related to viscosity at a shear rate of $\approx 50$ reciprocal seconds $(1 / \mathrm{s})$.

\section{Viscosity}

Viscosity significantly increased with the addition of tara gum across the 16 samples of fruit yogurt drink $(F(15,176)=1552.17, P<0.001$; linear contrast $P<0.001)$, see Figure 1 .

\section{Sensory evaluations of the test drinks}

The mean sensory ratings are presented in Table 1. Perceived thickness $(F(6.5,135.6)=65.38, P<0.001)$, creaminess $(F(4.8,90.4)=20.53, P<0.001)$ and stickiness $(F(5.5,104.1)=11.96, P<0.001)$ increased with the amount of tara gum in each sample (linear contrast $P<0.001$ for all) but rated sweetness, sourness and fruitiness did not differ across samples $(P>0.05$ for all). There was no effect of gender or test day on any of the ratings (all $P>0.05$ ) except for sourness, where there was a small but significant gender $\times$ day $\times$ sensory interaction $(F(8.0,168.7)=2.02, P=0.047)$ : some of the 16 samples were rated as slightly more or less sour depending on the gender of the participant and the day the rating was made, although there was no clear pattern to this interaction, which is likely to be a spurious finding, given the large number of potential interactions. 


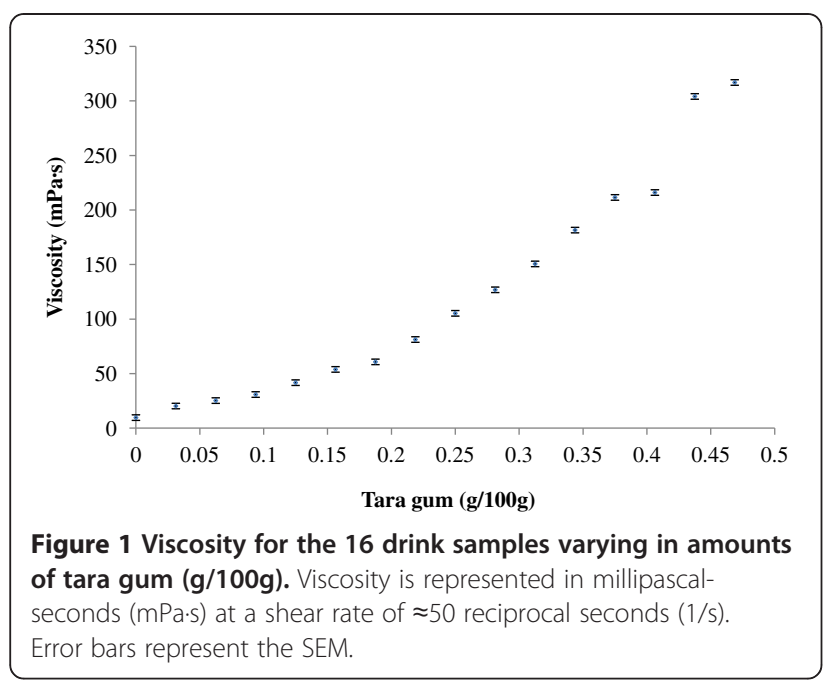

Relating sensory characteristics to viscosity

Table 1 details the correlations between the viscosity of each sample and their perceived sensory characteristics. Perceived thickness was strongly related to viscosity: as the viscosity of each sample increased, so did perceived thickness. Creaminess and stickiness ratings also increased with viscosity. There was a small but significant positive relationship between rated fruitiness and viscosity, indicating that there was a small increase in perceived fruitiness in the thicker samples, which was not picked up in the ANOVA (analysis of variance) on the fruitiness ratings. There was no relationship between the viscosity of the sample and perceived sweetness or sourness.

\section{Summary}

The results from study one indicate that participants, who are not trained sensory panellists, were able to perceive subtle differences in drink texture, and these differences were closely related to actual viscosity. This is in line with previous evidence that suggests that viscosity at a shear rate of $50 \mathrm{1} / \mathrm{s}$ relates to perceived thickness [34,35]. Small incremental increases in tara gum across the 16 drink samples produced measurable increases in viscosity (10 to $317 \mathrm{mPa} \cdot \mathrm{s}$, ranging from a fluid juice texture to a thicker yogurt drink texture, all consumed through a regular straw) and the participants perceived these subtle changes, although probably not at the level of every incremental increase. This sensitivity to subtle differences in viscosity is not surprising because texture is likely to be one sensory characteristic of food that reliably predicts the presence of nutrients, such as fat [36].

\section{Results: study two}

In study two, new participants, who were not trained sensory panellists, evaluated the sensory and hedonic characteristics of eight versions of a fruit yogurt drink, which varied in thickness (thin or thick), creamy flavour (low-creamy or creamy) and energy content (high- or lowenergy). The participants also rated how filling they expected each drink to be $(0=$ not at all, $100=$ extremely $)$ and its expected satiety. In the expected satiety measure, participants indicated the extent to which they expected each drink to suppress hunger until the next meal by selecting a portion of pasta and sauce that they thought would have the same effect on their hunger. Selecting a larger portion of pasta and sauce $(\mathrm{kcal})$ indicated that the drink was expected to be more satiating.

\section{Filling ratings}

The ANOVA revealed a significant effect of both thickness $(F(1,21)=98.98, P<0.001)$ and creamy flavour $(F(1,21)=20.89, P<0.001)$ on the extent to which the drinks were expected to be filling, independent of the drinks' energy content (interactions with energy all $P>0.05$ ), see Figure 2. Averaged across energy versions,

Table 1 Sensory ratings for each fruit yogurt drink sample used in study one

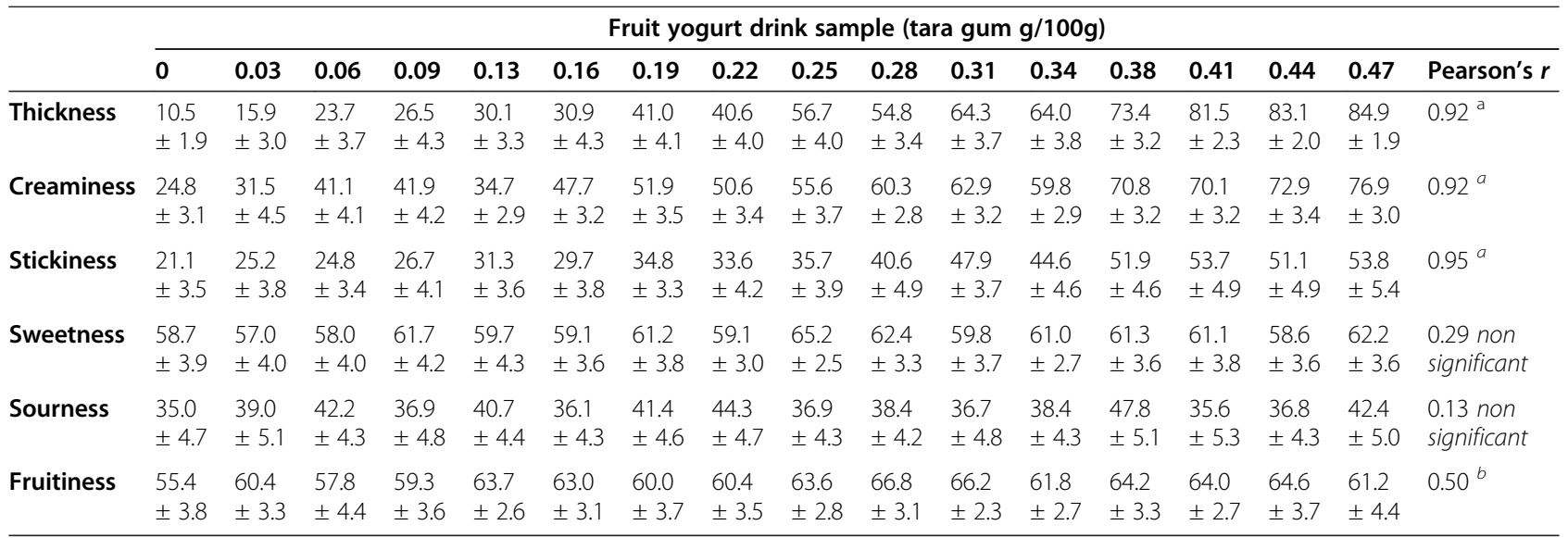

Numbers represent the mean visual analogue scale (VAS) rating $(0=$ not at all, $100=$ extremely) and associated SEM for each of the sensory evaluations across the 16 fruit yogurt drinks varying in the amount of tara gum $/ 100 \mathrm{~g}$. Pearson's $r$ shows the relationship between each sensory characteristic and the drink's measured viscosity. ${ }^{a}$ Correlation coefficient is significant at $P<0.001 .{ }^{b}$ Correlation coefficient is significant at $P<0.05$. 
the thick drinks $(M=64.6 \pm 2.2)$ were expected to be more filling than the thin drinks $(M=41.8 \pm 2.2)$ and the creamy versions of the $\operatorname{drink}(M=57.0 \pm 2.3)$ were expected to be more filling than the low-creamy versions $(M=49.4 \pm 1.8)$. There was no thick $\times$ creamy interaction $(F(1,21)=0.62, P=0.44)$ : increasing drink thickness increased the filling rating, which was enhanced by the addition of creamy flavour similarly across the thick and thin versions (see Figure 2). There was no overall effect of the drink's energy content on ratings of how filling the drink was expected to be $(F(1,21)=3.16, P=0.09)$.

\section{Expected satiety}

There was also a significant effect of drink thickness on expected satiety judgements $(F(1,21)=63.27, P<0.001)$ : the thick drinks had a greater expected satiety than the thin drinks, see Figure 3. However, the creamy versions of the drinks were not expected to suppress hunger any more than their low-creamy counterparts $(F(1,21)=0.60$, $P=0.45)$ and there was no thick $\times$ creamy interaction $(F(1,21)=2.60, P=0.12)$. There was no main effect of the drinks' energy content on expected satiety $(F(1,21)=0.52, P=0.48)$ but the analysis did reveal a significant thick $\times$ energy interaction $(F(1,21)=12.73$, $P=0.002)$. The interaction suggested that the high-energy thin drinks $(M=127.7 \pm 16.4)$ had a lower expected satiety than the low-energy thin drinks $(M=148.4 \pm 16.6)$, whereas the high-energy thick drinks $(M=269.2 \pm 33.9)$ and low-energy thick drinks $(M=266.2 \pm 33.9)$ were similarly expected to be the most satiating. However, Bonferroni adjusted comparisons revealed no significant difference in expected satiety between the high- and low-energy thin drinks $(P=0.42)$ or the high- and low-energy thick drinks

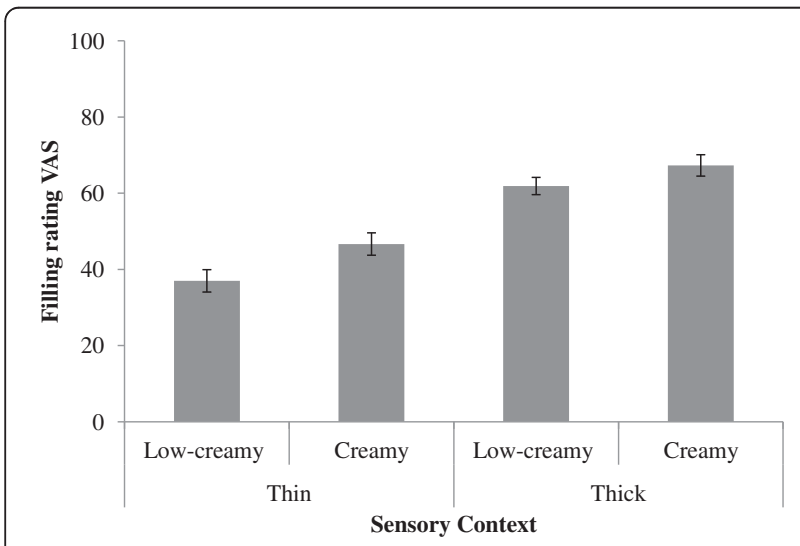

Figure 2 Filling VAS ratings ( $0=$ not at all, $100=$ extremely) \pm SEM for the drinks used in study two in the four sensory contexts, collapsed across drink energy content. The thick drinks were expected to be significantly more filling than the thin drinks $(P<0.001)$. The addition of creamy flavour increased this expectation, as the creamy drinks were rated as significantly more filling than the low-creamy versions $(P<0.001)$.

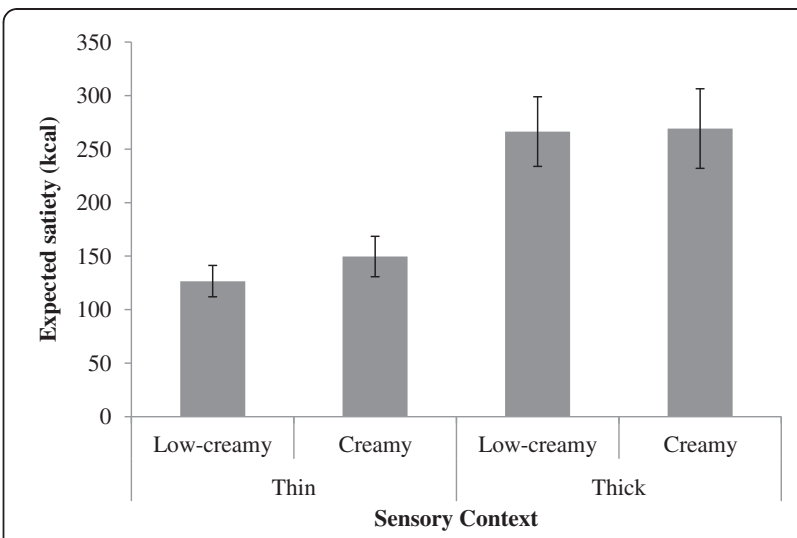

Figure 3 Mean portion of pasta and tomato sauce selected in the expected satiety task (kcal \pm SEM) in study two, collapsed across drink energy content. The thick drinks had a significantly larger expected satiety than the thin drinks $(P<0.001)$ and the addition of creamy flavour did not increase this expectation, as the expected satiety was similar for the low-creamy and creamy versions $(P>0.05)$.

$(P=0.99)$, only a difference between the expected satiety value based on the drinks' thickness (all $P<0.001$ ).

\section{Relating the filling rating to expected satiety}

We anticipated that the judgements measuring the extent to which the drinks were expected to be filling (VAS ratings) and the extent to which the drinks were expected to suppress hunger (expected satiety) would be related. Unexpectedly, Pearson's correlation indicated that for each of the eight drinks varying in thickness, creamy flavour and energy content, there was little relationship between the expectation that it would be filling and its expected satiety. Across the eight drinks, the two expectations were only significantly related for two of the drinks (for all others $P>0.05$ ). For the high-energy thick and creamy drink, the more filling it was expected to be, the greater its expected satiety $(r=0.53, P=0.011)$. However, the more filling the low-energy thick and low-creamy drink was expected to be, the lower its expected satiety $(r=-0.57, P=0.005)$. This suggests little relationship between the two expectations.

\section{Sensory and hedonic evaluations of the drinks}

ANOVAs revealed that the drinks differed on several sensory attributes (see Table 2). The thick drinks were rated as more thick $(F(1,21)=170.79, P<0.001)$, creamy $(F(1,21)=52.48, P<0.001)$ and sticky $(F(1,21)=40.96$, $P<0.001)$ than the thin drinks, and less fruity $(F(1,21)=$ $18.19, P<0.001)$. Drink texture did not affect sweetness ratings. The creamy drinks were rated as creamier $(F(1,21)=17.74, P>0.001)$, thicker $(F(1,21)=13.47$, $P=0.001)$ and slightly sweeter $(F(1,21)=6.40, P=0.02)$ than the low-creamy drinks. The addition of creamy flavour 
Table 2 Sensory evaluations of drinks used in study two across each sensory context

\begin{tabular}{lccccc}
\hline & \multicolumn{2}{c}{ Thin } & & \multicolumn{2}{c}{ Thick } \\
\cline { 2 - 3 } \cline { 5 - 6 } & Low-creamy & Creamy & & Low-creamy & Creamy \\
\hline Creamy & $35 . \pm 3.8$ & $51.4 \pm 3.5$ & & $66.9 \pm 2.9$ & $71.9 \pm 2.3$ \\
Fruity & $63.2 \pm 3.5$ & $66.4 \pm 3.4$ & & $49.8 \pm 4.3$ & $53.8 \pm 3.6$ \\
Pleasant & $57.6 \pm 3.6$ & $63.0 \pm 3.2$ & & $55.8 \pm 4.0$ & $57.4 \pm 5.9$ \\
Sticky & $33.4 \pm 4.2$ & $34.4 \pm 3.4$ & & $52.2 \pm 3.8$ & $55.8 \pm 4.0$ \\
Sweet & $58.3 \pm 3.1$ & $65.3 \pm 2.5$ & & $54.5 \pm 3.2$ & $61.4 \pm 2.8$ \\
Thick & $26.0 \pm 3.0$ & $37.3 \pm 2.3$ & & $68.0 \pm 3.0$ & $73.2 \pm 3.4$ \\
\hline
\end{tabular}

Evaluations are collapsed across high-energy and low-energy versions for the eight drinks and represent the mean VAS rating $(0=$ not at all, $100=$ extremely) and associated \pm SEM for the drinks in the four sensory contexts, varying in thickness and creamy flavour.

did not affect the perceived fruitiness or stickiness of the drinks. All the drinks were rated as similarly pleasant, regardless of thick texture, creamy flavour or energy content (all main effects and interactions $P>0.05$ ). There was no thick $\times$ creamy interaction for any of the sensory characteristics (all $P>0.05$ ). Overall, there was no main effect of drink energy on thick, creamy, sticky, fruity, sweet and pleasantness ratings for any of the drinks (all $P>0.05$ ). However, there was a small but significant thick $\times$ energy interaction for the creamy ratings $(F(1,21)=4.77$, $P=0.04)$. Bonferroni adjusted comparisons revealed that the high-energy thick drinks $(M=66.6 \pm 2.8)$ were rated as similarly creamy to the low-energy thick drinks $(M=72.4: P=0.35)$, but the high-energy thin drinks $(M=35.0 \pm 3.7)$ were rated as less creamy than the low-energy thin drinks $(M=50.8 \pm 3.1: P=0.003)$.

\section{Hunger, fullness and thirst pre- and post-test}

Rated hunger decreased $(F(1,21)=13.91, P=0.001)$ and rated fullness increased $(F(1,21)=110.70, P<0.001)$ from pre- to post-test. There was no difference in thirst from the beginning to the end of the session. Importantly, pre-test hunger ratings were not related to the filling ratings and expected satiety judgements across the eight drinks (all $P>0.05$ ).

\section{Summary}

The results from study two indicate that sensory characteristics can influence satiety expectations of a drink, independent of its actual energy content. Both creamy flavour and thick texture enhanced the expectation that a drink would be filling (the anticipated satiation that is expected to be experienced straight after consumption), but thick texture influenced this expectation more so than creamy flavour. Thick texture alone influenced the expectation that the yogurt drink would suppress hunger over time, as the thick drinks had a greater expected satiety than the thin versions and there was no difference in expected satiety between the low-creamy and creamy drinks. Interestingly, for each drink, the participants' expectations that it would be filling and its expected satiety value were generally not related, suggesting that participants used different strategies to make these two judgements.

\section{Discussion}

The results of these studies suggest that consumers are sensitive to subtle changes in the sensory characteristics of a drink and that thick texture and creamy flavour can be manipulated to enhance satiety expectations, but that their contributions are not equal. Our findings also indicate that beverages can differ in the extent to which they are expected to be satiating, regardless of the actual calories that they contain. This is important because, at least in the short term, manipulating the expected and not the actual calories of a product can influence subjective appetite [26], subsequent ghrelin response [37] and intake at a later meal $[38,39]$. Although this study did not measure the actual satiating value of the drinks used, Yeomans and Chambers [33] found that thick and creamy sensory characteristics enhance the satiety value of a drink, but only when those characteristics correctly predicted the delivery of nutrients. Taken together, this suggests that both high- and low-energy drinks that are made to taste thicker will be expected to be more satiating, but this expectation may have different effects on satiety, depending on the actual energy content that is delivered post-consumption.

So why then should thickness be a good predictor of satiety in a beverage? For one, human adults have already had a wealth of experience with foods across their lifetime and often liquids that are more viscous do have more calories (such as honey compared to water). For example, variation in the energy density of breast milk has been shown to correlate with viscosity [40] and this variability might lead to learnt associations between perceived thickness and satiety [41]. The natural flavour of milk would be expected to be part of this association but one possibility is that increased oral exposure experienced with more viscous liquids makes it easier to associate the sensory characteristics of a thicker beverage, such as flavour, with its postingestive consequences [42,43]; creamy flavour alone is not likely to increase oral exposure, which may make it a less effective cue for learning when it is independent of an increase in viscosity.

In study two, the addition of creamy flavour did not impact satiety expectations as much as a thick texture, so it is possible that creamy flavour is not a good predictor of a food's caloric value. Reduced-fat and 'diet' food products, such as low-fat yogurts, are often produced to have the same 'creamy' flavour as the full-calorie versions to increase satisfaction and palatability. An inconsistent relationship between the sensory characteristics of a food and its energetic value may weaken the associations formed between them [44-46]. We could have taken a measure 
of participants' reported previous experience with these types of diet food products to see if this affected the ability of the creamy flavour cue to generate satiety expectations. However, our results consistently indicated that, as the viscosity of a yogurt drink increased, it was perceived to be thicker but also creamier and stickier. It seems likely that rating the drinks as 'creamy' is simply not a sufficiently sensitive measure for the general consumer, and is confounded by the complex sensory profile of creamy dairy products, which is based on a combination of flavour and texture attributes [47]. Furthermore, the creamy drinks were not only rated as creamier than the low-creamy drinks, but also thicker, so we cannot rule out the possibility that the creamy drinks were instead expected to be more filling, based on their enhanced perceived thickness.

The complexity of the creamy sensory characteristic may have contributed to any discrepancies between the highand low-energy versions of the drinks. Energy content was not predicted to influence satiety expectations, as the highand low-energy versions of the drinks were designed to be matched in terms of perceived flavour and texture and the drink samples were only tasted and not consumed in full portions. However, there was evidence in the expected satiety measure that the low-energy thin drinks were expected to be more satiating than the high-energy thin drinks. This difference maps onto the finding that the lowenergy thin drinks were also rated as creamier than the high-energy thin drinks, possibly because, overall, the lowenergy drinks were slightly more viscous and contained slightly more fromage frais than the high-energy drinks (see study two 'test drinks' in the method section for viscosities and ingredients), and this difference may have been more noticeable in the thin versions. This highlights the importance of matching high- and lowenergy versions of test food for characteristics, such as thickness and creaminess, in satiety studies.

Within a liquid context, thicker drinks have been shown to suppress hunger to a greater extent than a caloriematched thin version [31,32] and this could be because the thicker drinks were expected to be more satiating. However, an alternative explanation for this could be that the thickener used to manipulate viscosity had a post-ingestive effect. If this is the case, the effect of increased satiety expectations generated by these texture cues may be redundant. Water-soluble polysaccharides used to increase liquid viscosity, such as tara gum and guar gum, also increase its dietary fibre content and the addition of a small quantity of fibre ( 0.82 to $1.5 \mathrm{~g}$ per $100 \mathrm{~g}$ of a drink) has been shown to increase the short-term satiety value of a beverage, with delayed gastric emptying implicated as a possible mechanism $[48,49]$. However, what was not considered in these studies is that the addition of fibre also increases oral viscosity; moreover, the quantities of fibre used were larger than those used to manipulate thickness in the current study. One possibility is that expectations of satiety generated by a thicker liquid actually contribute to the increased satiety value of these fibre-enhanced beverages. Expectations generated by the oral viscosity and anticipated gastric viscosity of a solid and liquid food have recently been shown to influence subjective appetite, intake and gastrointestinal function [10], highlighting the potential of the satiety-relevant expectations in influencing the postingestive development of satiety. It is unlikely that small differences in the viscosity of a beverage would persist postingestion owing to the influence of gastric dilution [49]; instead beliefs about the post-ingestive effects of the beverage may important.

An unexpected outcome of study two was the lack of relationship between the expectation that a drink will be filling and its expected satiety. There is evidence to suggest that people differ in the sensory information that they use to guide food intake [22] and one possibility is that our participants were using different strategies to make these two judgements. However, the way in which individuals differentially use flavour and texture cues to generate satiety expectations is not clear. In this study, it appears that both textural and flavour cues contributed to the extent to which the drinks were expected to be filling, whereas only drink thickness influenced expected satiety. In our measure of expected satiety, participants compared the anticipated satiating effect of a fruit yogurt drink to that of pasta and tomato sauce, whereas the expectation that the drink will be filling was measured on a rating scale. One possibility is that when the participants imagined the expected satiety of each drink sample in comparison to pasta and sauce, texture was a more relevant cue for satiety. Creamy flavour may have been overlooked because it is not a relevant sensory characteristic of pasta and sauce. Furthermore, participants may have found it harder to imagine a suppression of hunger in the expected satiety tasks than an increase in fullness in the rating measure. In future, it would be useful to measure the method of adjustment comparisons and VAS ratings for both types of expectations generated by sensory cues, to see how they compare.

Finally, it is important to note that this research had a repeated measures design and all the participants tasted each of the drinks during the session. It is possible that the influence of the drinks' sensory characteristics on satiety expectations was more pronounced, due to contrast effects, and from this study it is not clear how these subtle sensory differences would influence expectations in a single drink product day to day when not tasted alongside a similar product.

\section{Conclusion}

Overall, this research indicates that people are sensitive to subtle changes in the sensory quality of a drink and 
that these characteristics can increase the expectation that a drink will be filling (anticipated satiation) and suppress hunger over time (expected satiety). It appears that thick texture, rather than creamy flavour, had the biggest influence on satiety expectations and this was independent of the drink's actual energy content. Therefore, enhancing the texture of high-energy drinks to be more satiety relevant may be one way to increase their weak satiating capacity. These findings also highlight the importance of matching sensory characteristics, such as texture, in studies that manipulate the energy density of foods or the sensory context of energy-matched products.

\section{Method: study one Participants}

Twenty-four (12 male) participants were recruited from a volunteer database of staff and students at the University of Sussex. Participants were aged between 19 and 26 years $($ mean $=21.0, \mathrm{SD}=2.0$ ) and were non-obese (mean $=23.3 \mathrm{~kg} / \mathrm{m}^{2}, \mathrm{SD}=2.8$ ) with a mean dietary restraint score of $6.3(\mathrm{SD}=3.6)$ for females and 4.2 $(\mathrm{SD}=2.7$ ) for males (measured using the three-factor eating questionnaire (TFEQ) [50]). Male and female participants did not differ in age, restraint or body mass index (BMI). They were selected to be healthy non-smokers, not currently dieting or taking prescription medication, with no eating disorders and without allergies or aversions to any of the test foods. The research was approved by the University of Sussex, Life Science Research Ethics Board. All participants gave consent to take part in a study entitled 'Investigating the interaction between mood and taste' and received $£ 10$ payment on completion.

\section{Fruit yogurt drinks}

All test drinks were designed and prepared in the Ingestive Behaviour Unit at the University of Sussex and consisted of two training drinks and 16 test drinks made from the same low-energy fruit yogurt base (see Table 3 ). Thickness was manipulated with the addition of tara gum (Kaly's Gastronomie, France), a naturally occurring nonionic polysaccharide commonly used commercially as a thickening agent and stabiliser. The amount of tara gum ranged from 0.0 to $0.47 \mathrm{~g} / 100 \mathrm{~g}$ portion of the drink base, increasing in $0.03 \mathrm{~g}$ increments across the 16 drinks. The training drinks were an example of a 'thin' drink (water) and a 'thick' drink (the fruit yogurt drink with $0.63 \mathrm{~g} / 100 \mathrm{~g}$ tara gum added). All samples were kept at 1 to $5^{\circ} \mathrm{C}$ and used within 4 days of preparation.

\section{Measures \\ Viscosity}

Rheological measurements were taken at the University of Birmingham, Department of Chemical Engineering, at $5^{\circ} \mathrm{C}$ on a Bohlin Rotational Rheometer (Malvern Instruments Ltd) using parallel-plate geometry (60 mm diameter) and a gap size of $1.0 \mathrm{~mm}$. Flow behaviour was measured at shear rates from 0.001 to $8001 / \mathrm{s}$ and back down in reverse sequence for the same duration, with three repeats using a fresh sample each time. Tara gum solutions typically show non-Newtonian shear thinning behaviour [51], which means that their viscosity is not constant but is dependent on rate of flow (the shear rate) during measurement. For this reason, viscosity reported in the results section is an average of the data collected at a shear rate of $52.61 / \mathrm{s}$ (referred to as $\approx 501 / \mathrm{s}$ ), which was the actual shear rate the rheometer achieved when aiming for $501 / \mathrm{s}$, which is thought to best represent in-mouth viscosity [34,35]. Although shear rates of above 1000 $1 / \mathrm{s}$ have been associated with in-mouth viscosity [52], the highest shear rate that could be obtained for the samples was $8001 / \mathrm{s}$, as all the samples were relatively thin and liable to run off the rheometer plate. Parallel-plate geometry was used to spread the force created under shear over a wider area, allowing a larger range of shear rates to be achieved accurately.

\section{Sensory ratings}

Sensory evaluations of the 16 samples were collected in the form of VAS ratings using the Sussex Ingestion Pattern Monitor (SIPM) [53] running on a Dell PC using the Windows XP professional operating system. Participants were asked 'How <target> is sample X?' with the targets 'thick', 'sweet,' 'sour,' 'sticky', 'fruity' and 'creamy'. Participants were instructed to indicate the extent that each sample was $<$ target $>$ by dragging a marker along a $100 \mathrm{~mm}$ line. The scale was always anchored with the words 'Not at all < target $>$ '

Table 3 Ingredients and basic nutritional composition of the high- and low-energy fruit yogurt drink base

\begin{tabular}{|c|c|c|c|c|}
\hline \multirow[t]{2}{*}{ Ingredients per $100 \mathrm{~g}$ portion } & \multicolumn{2}{|c|}{ Low-energy $^{a}$} & \multicolumn{2}{|c|}{ High-energy $^{a}$} \\
\hline & weight (g) & kcal & weight (g) & kcal \\
\hline Peach and passion fruit juice ${ }^{b}$ & 31.3 & 14.4 & 31.3 & 14.4 \\
\hline Peach squash ${ }^{c}$ & 10.9 & 1.2 & 10.9 & 1.2 \\
\hline $0.1 \%$ fat Fromage frais ${ }^{b}$ & 17.2 & 8.6 & 9.4 & 4.7 \\
\hline Water & 40.6 & 0 & 31.2 & 0 \\
\hline Maltodextrin ${ }^{d}$ & 0 & 0 & 17.2 & 65.3 \\
\hline Aspartame ${ }^{e}$ & 0.03 & 0 & 0 & 0 \\
\hline Yellow colour ${ }^{f}$ & 3 drops & 0 & 0 & 0 \\
\hline Red colour ${ }^{f}$ & 1 drop & 0 & 0 & 0 \\
\hline Total & $100 \mathrm{~g}$ & 24.2 & $100 \mathrm{~g}$ & 85.6 \\
\hline
\end{tabular}

${ }^{a}$ Low-energy drinks were used in study one and both high- and low-energy drinks were used in study two.

${ }^{b} \mathrm{~J}$ Sainsbury's plc, London, UK.

${ }^{c}$ Robinsons, Britvic, UK.

${ }^{d}$ Cargill, UK.

${ }^{e}$ Aspartame Powder, Ajinomoto Sweeteners Europe.

${ }^{f}$ Silverspoon, British Sugar, UK. 
(0) and 'Extremely <target>' (100). The presentation of each question was randomised.

\section{Procedure}

Test sessions were scheduled between 10.30 am and 12.00 noon or between $2.30 \mathrm{pm}$ and $4.00 \mathrm{pm}$, Monday to Friday. To minimise differences in hunger, participants were instructed not to consume any food or drink (excluding water) for two hours before they were due in the laboratory. Participants then underwent a brief training task to introduce them to the idea of rating a drink's 'thickness' and provide a reference standard. In the training task, participants were presented with an example of the thickest and the thinnest sample they would taste throughout the session. Participants were instructed to take a small mouthful of a sample through a straw, to hold the sample in their mouth while they counted to three and then swallow. Some research suggests that samples should be swallowed immediately, to reduce dilution by saliva and temperature equilibration, which can affect rheological properties of the food [54]. However, this technique significantly reduces the sensory exposure and oro-sensory sensitivity of the participants [55]. By allowing participants three seconds of oral exposure, this allowed some degree of sensitivity whilst maintaining a level of standardisation across all samples and participants. After swallowing, participants rated the thickness of the sample and were then prompted to take a sip of water. All participants rated the thickest sample first.

Following the training, participants were presented with a tray of 16 samples of the yogurt fruit drink and were required to taste each sample, holding the drink in the mouth for three seconds before swallowing. The samples were presented in $25 \mathrm{~g}$ portions in a small clear glass with a straw and labelled A to P. After each taste, participants completed a series of VAS ratings, assessing the sensory characteristics of each sample. Participants were prompted to take a sip of water before moving on to the next sample. The order of presentation of the samples was randomised across all participants and sessions.

Due to the large number of samples to be tasted, participants completed the tasting session twice on two nonconsecutive days, to check that their sensory evaluations were consistent. Each test session lasted 30 minutes and participants completed the two sessions at a similar time of day. After the final session, the participant's age, weight and height were recorded. Finally, participants completed questions pertaining to the purpose of the study, were debriefed, thanked and paid.

\section{Data analysis}

The main outcome measures were the actual viscosity of the samples thickened with tara gum measured using rheometry and the perceived sensory characteristics evaluated by volunteers. A one-factor independent sample ANOVA assessed the effect of tara gum on viscosity across the 16 test drinks.

A three-way mixed ANOVA was conducted for each sensory evaluation to assess the effect of added tara gum (16 levels) on the sensory judgements while controlling for test day (1 or 2) and gender (male or female participants). Where sphericity was not assumed Greenhouse-Geisser $(\varepsilon<0.75)$ or Huynd-Feldt $(\varepsilon>0.75)$ corrected degrees of freedom and $P$ values are presented. Means and SEM are presented throughout. The relationship between viscosity at $\approx 501 / \mathrm{s}$ and each of the sensory evaluations were investigated using Pearson's correlations.

\section{Method: study two \\ Participants}

Twenty-five participants (9 male) were staff and students at the University of Sussex, recruited from the same volunteer database as study one and conformed to the same selection criteria but had not taken part in study one. Participants were aged 19 to $26(M=21.0, S D=2.7)$, and were non-obese (mean BMI $=22.8 \mathrm{~kg} / \mathrm{m}^{2}, \mathrm{SD}=3.3$ ) with an average TFEQ restraint score of $5.7(\mathrm{SD}=4.9)$ for males and 6.4 (SD = 3.9) for females; these characteristics were similar between males and females. The study was approved by the University of Sussex, Life Science Research Ethics Board. All participants gave written consent to take part in a study entitled 'Investigating the interaction between mood and taste' and received $£ 6$ payment on completion.

\section{Test drinks}

The fruit yogurt drinks were designed with four satietyrelevant sensory contexts varying in thickness (thin or thick) and creamy flavour (low-creamy or creamy) with high-energy (HE) and low-energy (LE) versions for each. Table 3 lists the ingredients and basic nutritional composition of the low-energy and high-energy fruit yogurt drink bases. Creamy flavour was enhanced by the addition of vanilla extract (Nielsen-Massey, NL: 19 drops/100g) and milk caramel flavouring (Synrise, DE: 0.16g/100g) and thickness was increased by manipulating the amount of tara gum $(\mathrm{g} / 100 \mathrm{~g})$ in each drink (low-creamy/thin LE: 0.09g, low-creamy/thin HE: 0g, creamy/thin LE: 0.09g, creamy/thin HE: $0 \mathrm{~g}$, low-creamy/thick LE: $0.38 \mathrm{~g}$, lowcreamy/thick HE: $0.31 \mathrm{~g}$, creamy/thick LE $0.38 \mathrm{~g}$, creamy/ thick HE: $0.31 \mathrm{~g}$ ); more tara gum was added to the LE versions of the drinks, to account for the small increase in thickness caused by the addition of maltodextrin to the HE versions and rheological measurements were relatively well matched across high- and low-energy drinks in the thin $(\mathrm{LE}=20.8 \mathrm{mPa} \cdot \mathrm{s}, \mathrm{HE}=30.8 \mathrm{mPa} \cdot \mathrm{s})$ and thick $(\mathrm{LE}=$ $221.5 \mathrm{mPa} \cdot \mathrm{s}, \mathrm{HE}=184.0 \mathrm{mPa} \cdot \mathrm{s})$ contexts. The thick drinks 
were similar in viscosity to the sample containing 0.34 to $0.40 \mathrm{~g} / 100 \mathrm{~g}$ tara gum in study one, and the thin drinks were similar in viscosity to the sample containing 0.03 to $0.09 \mathrm{~g} / 100 \mathrm{~g}$ in study one. Colour was matched between all the drink samples by the addition of small quantities of natural food colouring (see Table 3).

\section{Measures}

\section{Hunger, fullness and thirst}

VAS ratings of appetite were collected using SIPM and had the same format as the sensory ratings in study one. Participants rated how 'hungry', 'full' and 'thirsty' they were from not at all (0) to extremely (100) and these ratings were embedded amongst other distracter 'mood' questions: calm, happy, clearheaded, anxious, nauseous, headachy, tired, energetic, and alert. Only the appetite questions were analysed and all questions were presented in a randomised order.

\section{Sensory evaluations and filling rating}

Participants also made VAS ratings of how 'sweet,' 'thick', 'creamy', 'pleasant,' 'sticky' and 'fruity' the drinks were, as well as rating the extent to which each sample was expected to be filling. All ratings were from 'not at all' (0) to 'extremely' (100) and were presented in a random order.

\section{Expected satiety}

The measurement of expected satiety was based on a computer-based methodology developed by Brunstrom et al. [25]. The program was written in Visual Basic software displayed on a Dell laptop computer running Windows 7, and all testing was in a windowless airconditioned testing cubicle. Participants were presented with the set of eight drink samples and a 320 g portion of the drink base in a clear plastic bottle with a fastened lid representing a standard drink serving. Participants were prompted by on screen instructions to 'Take a sip of sample $X^{\prime}$ using the straw provided. Then, they were presented with an image of pasta and tomato sauce and participants were instructed, 'Imagine you are going to consume the whole bottle of sample $\mathrm{X}$ for lunch. How much pasta would you need to eat to match the effect of sample $\mathrm{X}$ on your hunger?' Participants used the left and right arrow keys on the keyboard to move through images and increase or decrease the amount of pasta and sauce displayed. There were 101 images of pasta and sauce in total ('Egg penne pasta': J Sainsbury plc, UK; 'Sundried stir-in tomato sauce': Mars Food, UK) ranging from $10 \mathrm{kcal}$ in image 0 to 1000 $\mathrm{kcal}$ in image 100. Portion sizes increased across images in logarithmic steps, such that images $0,20,40,60,80,100$ showed $10 \mathrm{kcal}, 25.1 \mathrm{kcal}, 63.1 \mathrm{kcal}, 158.5 \mathrm{kcal}, 398.1 \mathrm{kcal}$, and $1000 \mathrm{kcal}$ respectively. Participants selected enter when they had selected their required portion size. All images were taken by a high-resolution digital camera mounted above a 255-mm diameter white plate and care was taken to maintain consistency of lighting and camera angle across each photograph. All participants confirmed that they had eaten pasta and tomato sauce before.

\section{Procedure}

Participants completed one test session that lasted approximately 45 minutes and was scheduled on a weekday between $10.30 \mathrm{am}$ and $12.30 \mathrm{pm}$ or $2.30 \mathrm{pm}$ and $4.30 \mathrm{pm}$. As in study one, participants were required to consume only water for 2 hours prior to attending the lab and they completed the session in an air-conditioned testing cubicle with a PC computer.

To begin, participants rated their subjective appetite disguised as a series of 'mood questions'. They were then presented with $25 \mathrm{~g}$ portions of the eight test drinks each in a small clear glass labelled $\mathrm{A}$ to $\mathrm{H}$ and were informed that they would taste each sample twice using the straws provided. Participants first tasted each sample to make the sensory VAS ratings and to rate how filling they expected it to be, and then tasted the samples for a second time to complete the expected satiety task. Half of the participants completed the two tasks in the reverse order and all were provided with water throughout. Once the tastings were finished, participants completed a final set of appetite ratings and were debriefed, thanked and received their compensatory payment.

\section{Data analysis}

Appetite ratings were taken before and after the tasks as a difference in subjective appetite prior to the test may have influenced task performance. A one-factor mixed ANOVA assessed the effect of time (pre- and post-test) on the three measures of appetite and a series of Pearson's correlations was used to assess the relationship between pre-test hunger, fullness and thirst to the anticipated fullness and expected satiety of the drinks.

A series of three-way mixed ANOVAs and Bonferroni adjusted comparisons contrasted the effect of drink thickness (thin or thick), creamy flavour (low-creamy or high-creamy) and energy context (high or low) on each of the expectations (anticipated fullness and expected satiety) and the sensory and hedonic ratings. The expected satiety scores represent the quantity (in kcal) of pasta and tomato sauce presented in the image selected by the participants. These data were log transformed to improve normality for the analysis. However, the descriptive data and mean values were presented in $\mathrm{kcal}$ to aid interpretation. It was predicted that the expectation that a drink would be filling would be strongly related to its expected satiety, and this was tested using a series of Pearson's correlations to assess the relationship between these two expectations across the eight test drinks. 
Initially, these analyses also included task order (VAS ratings then expected satiety or expected satiety then VAS ratings) as a factor. However, as there was no significant effect or interactions with this factor it was removed from the final analysis. Twenty-five participants took part in the study but the data from three participants were removed as their expectation values (filling rating or expected satiety) were more than two standard deviations from the mean. Consequently, data from 22 participants were included, leaving 16 females and just 6 males in the final analysis. For this reason gender was not included as a factor, owing to an inadequate number of males. Means and SEM are presented throughout.

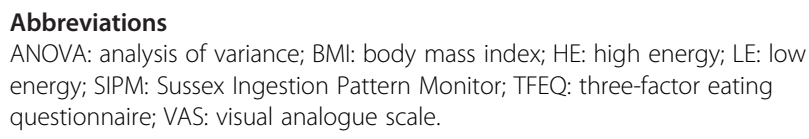

ANOVA: analysis of variance; BMI: body mass index; HE: high energy; LE: low energy; SIPM: Sussex Ingestion Pattern Monitor; TFEQ: three-factor eating questionnaire; VAS: visual analogue scale.

\section{Competing interests}

The authors declare that they have no competing interests.

\section{Authors' contributions}

MY, LC and KMCC designed the study. KMcC prepared the study materials, collected and analysed the human data and viscometry, and drafted the manuscript. JB programmed the expected satiety task. All authors contributed to and approved the final manuscript.

\section{Acknowledgements}

This research was funded by the BBSRC DRINC initiative and conducted as part of a PhD studentship. The rheological measurements were conducted at the University Of Birmingham Department Of Chemical Engineering, with the help of Professor lan Norton, Dr Tom Mills and Dr Jennifer Norton of The Microstructure Group. Dr Tom Mills helped to set up, run and interpret the viscosity measurements.

\section{Author details}

${ }^{1}$ School of Psychology, Pevensey Building, University of Sussex, Brighton BN1 $9 \mathrm{QH}$, UK. ${ }^{2}$ Nutrition and Behaviour Unit, School of Experimental Psychology, University of Bristol, Priory Road, Bristol BS8 1TU, UK.

Received: 21 August 2012 Accepted: 2 October 2012

Published: 31 October 2012

\section{References}

1. Ng SW, Ni Mhurchu C, Jebb SA, Popkin BM: Pattern and trends of beverage consumption among children and adults in Great Britain, 1986-2009. Br J Nutr 2012, 108(03):536-551.

2. Mattes RD: Beverages and positive energy balance: the menace is the medium. Int J Obes (Lond) 2006, 30:S60-S65.

3. Hulshof T, Degraaf C, Weststrate JA: The effects of preloads varying in physical state and fat-content on satiety and energy-intake. Appetite 1993, 21(3):273-286.

4. Leidy HJ, Apolzan JW, Mattes RD, Campbell WW: Food form and portion size affect postprandial appetite sensations and hormonal responses in healthy, nonobese, older adults. Obesity 2010, 18(2):293-299.

5. Mattes RD: Dietary compensation by humans for supplemental energy provided as ethanol or carbohydrate in fluids. Physiol Behav 1996, 59(1):179-187.

6. Mourao DM, Bressan J, Campbell WW, Mattes RD: Effects of food form on appetite and energy intake in lean and obese young adults. Int $J$ Obes (Lond) 2007, 31(11):1688-1695.

7. Tournier A, Louis-Sylvestre J: Effect of the physical state of a food on subsequent intake in human subjects. Appetite 1991, 16(1):17-24.

8. Almiron-Roig E, Chen Y, Drewnowski A: Liquid calories and the failure of satiety: how good is the evidence? Obes Rev 2003, 4(4):201-212.
9. Almiron-Roig E, Flores SY, Drewnowski A: No difference in satiety or in subsequent energy intakes between a beverage and a solid food. Physiol Behav 2004, 82(4):671-677.

10. Cassady BA, Considine RV, Mattes RD: Beverage consumption, appetite, and energy intake: what did you expect? Am J Clin Nutr 2012, 95(3):587-593.

11. Mattes R: Soup and satiety. Physiol Behav 2005, 83(5):739-747.

12. Zijlstra N, Mars M, de Wijk RA, Westerterp-Plantenga MS, de Graaf C: The effect of viscosity on ad libitum food intake. Int J Obes (Lond) 2008, 32(4):76-683.

13. Martin CK, Anton SD, Walden H, Arnett C, Greenway FL, Williamson DA: Slower eating rate reduces the food intake of men, but not women: implications for behavioral weight control. Behav Res Ther 2007, 45(10):2349-2359.

14. Cecil JE, Francis J, Read NW: Relative contributions of intestinal, gastric, oro-sensory influences and information to changes in appetite induced by the same liquid meal. Appetite 1998, 31(3):377-390.

15. Cecil JE, Francis J, Read NW: Comparison of the effects of a high-fat and high-carbohydrate soup delivered orally and intragastrically on gastric emptying, appetite, and eating behaviour. Physiol Behav 1999, 67(2):299-306.

16. Giduck SA, Threatte RM, Kare MR: Cephalic reflexes - their role in digestion and possible roles in absorption and metabolism. J Nutr 1987, 117(7):1191-1196

17. Mattes RD: Physiologic responses to sensory stimulation by food: nutritional implications. J Am Diet Assoc 1997, 97(4):406.

18. Mattes RD: Orosensory considerations. Obesity 2006, 14:164S-167S.

19. Woods SC: The eating paradox - how we tolerate food. Psychol Rev 1991 98(4):488-505.

20. Birch LL, Deysher M: Conditioned and unconditioned caloric compensation - evidence for self-regulation of food-intake in youngchildren. Learn Motiv 1985, 16(3):341-355.

21. Booth DA, Mather P, Fuller J: Starch content of ordinary foods associatively conditions human appetite and satiation, indexed by intake and eating pleasantness of starch-paired flavors. Appetite 1982, 3(2):163-184

22. Shaffer SE, Tepper BJ: Effects of learned flavor cues on single meal and daily food-intake in humans. Physiol Behav 1994, 55(6):979-986.

23. Yeomans MR, Weinberg $L$, James $S$ : Effects of palatability and learned satiety on energy density influences on breakfast intake in humans. Physiol Behav 2005, 86(4):487-499.

24. Blundell J, de Graaf C, Hulshof T, Jebb S, Livingstone B, Lluch A, Mela D, Salah S, Schuring E, van der Knaap H, Westerterp M: Appetite control: methodological aspects of the evaluation of foods. Obes Rev 2010, 11(3):251-270.

25. Brunstrom JM, Shakeshaft NG, Scott-Samuel NE: Measuring 'expected satiety' in a range of common foods using a method of constant stimuli. Appetite 2008, 51(3):604-614.

26. Brunstrom JM, Brown S, Hinton EC, Rogers PJ, Fay SH: 'Expected satiety' changes hunger and fullness in the inter-meal interval. Appetite 2011, 56(2):310-315.

27. Brunstrom JM, Rogers PJ: How many calories are on our plate? Expected fullness, not liking, determines meal-size selection. Obesity 2009, 17(10):1884-1890.

28. Brunstrom JM, Shakeshaft NSG: Measuring affective (liking) and nonaffective (expected satiety) determinants of portion size and food reward. Appetite 2009, 52(1):108-114.

29. Piqueras-Fiszman B, Spence C: The weight of the container influences expected satiety, perceived density, and subsequent expected fullness. Appetite 2012, 58(2):559-562.

30. Hogenkamp PS, Stafleu A, Mars M, Brunstrom JM, de Graaf C: Texture, not flavor, determines expected satiation of dairy products. Appetite 2011, 57(3):635-641.

31. Mattes RD, Rothacker $\mathrm{D}$ : Beverage viscosity is inversely related to postprandial hunger in humans. Physiol Behav 2001, 74(4-5):551-557.

32. Zijlstra N, Mars M, de Wijk RA, Westerterp-Plantenga MS, Holst JJ, de Graaf C: Effect of viscosity on appetite and gastro-intestinal hormones. Physiol Behav 2009, 97(1):68-75.

33. Yeomans MR, Chambers L: Satiety-relevant sensory qualities enhance the satiating effects of mixed carbohydrate-protein preloads. Am J Clin Nutr 2011, 94(6):1410-1417. 
34. Shama F, Sherman P: Identification of stimuli controlling the sensory evaluation of viscosity II oral methods. J Texture Stud 1973, 4:111-118.

35. Sherman P: Hydrocolloid solutions and gels - sensory evaluation of some textural characteristics and their dependence on rheological properties. Prog Food Nutr Sci 1982, 6(1-6):269-284.

36. Drewnowski A: The new fat replacements - a strategy for reducing fat consumption. Postgrad Med 1990, 87(6):111.

37. Crum AJ, Corbin WR, Brownell KD, Salovey P: Mind over milkshakes: mindsets, not just nutrients, determine ghrelin response. Health Psychol 2011, 30(4):424-429.

38. Shide DJ, Rolls BJ: Information about the fat-content of preloads influences energy-intake in healthy women. J Am Diet Assoc 1995, 95(9):993-998

39. Wooley OW, Wooley SC, Dunham RB: Can calories be perceived and do they affect hunger in obese and nonobese humans. J Comp Physiol Psych 1972, 80(2):250.

40. Picciano MF: Human milk: nutritional aspects of a dynamic food. Biol Neonate 1998, 74(2):84-93.

41. Davidson TL, Swithers SE: A Pavlovian approach to the problem of obesity. Int J Obes (Lond) 2004, 28(7):933-935.

42. de Graaf C, Kok FJ: Slow food, fast food and the control of food intake. Nat Rev Endocrinol 2010, 6(5):290-293.

43. Mars M, Hogenkamp PS, Gosses AM, Stafleu A, De Graaf C: Effect of viscosity on learned satiation. Physiol Behav 2009, 98(1-2):60-66.

44. Rudenga KJ, Small DM: Amygdala response to sucrose consumption is inversely related to artificial sweetener use. Appetite 2012, 58(2):504-507.

45. Swithers SE, Doerflinger A, Davidson TL: Consistent relationships between sensory properties of savory snack foods and calories influence food intake in rats. Int J Obes (Lond) 2006, 30(11):1685-1692.

46. Swithers SE, Ogden SB, Davidson TL: Fat substitutes promote weight gain in rats consuming high-fat diets. Behav Neurosci 2011, 125(4):512-518.

47. Kirkmeyer SV, Tepper BJ: Consumer reactions to creaminess and genetic sensitivity to 6-n-propylthiouracil: a multidimensional study. Food Qual Prefer 2005, 16(6):545-556.

48. Ibrugger S, Kristensen M, Mikkelsen MS, Astrup A: Flaxseed dietary fiber supplements for suppression of appetite and food intake. Appetite 2012, 58(2):490-495.

49. Marciani L, Gowland PA, Spiller RC, Manoj P, Moore RJ, Young P, Al-Sahab S, Bush D, Wright J, Fillery-Travis AJ: Gastric response to increased meal viscosity assessed by echo-planar magnetic resonance imaging in humans. J Nutr 2000, 130(1):122-127.

50. Stunkard AJ, Messick S: The three-factor eating questionnaire to measure dietary restraint, disinhibition and hunger. J Psychosom Res 1985, 29(1):71-83.

51. Wu Y, Cui W, Eskin NAM, Goff HD: An investigation of four commercial galactomannans on their emulsion and rheological properties. Food Res Int 2009, 42(8):1141-1146.

52. Koliandris AL, Morris C, Hewson L, Hort J, Taylor AJ, Wolf B: Corresponding author contact information: Correlation between saltiness perception and shear flow behaviour for viscous solutions. Food Hydrocolloid 2010, 24(8):792-799.

53. Yeomans MR: Rating changes over the course of meals: what do they tell us about motivation to eat? Neurosci Biobehav $R$ 2000, 24(2):249-259.

54. Bourne MC: Relationship between rheology and food texture. In Engineering and Food for the 21st Century. Boca Raton: CRC Press-Taylor \& Francis Group; 2002:291-306.

55. de Wijk RA, Engelen L, Prinz JF: The role of intra-oral manipulation in the perception of sensory attributes. Appetite 2003, 40(1):1-7.

doi:10.1186/2044-7248-1-20

Cite this article as: McCrickerd et al: Subtle changes in the flavour and texture of a drink enhance expectations of satiety. Flavour 2012 1:20.

\section{Submit your next manuscript to BioMed Central and take full advantage of:}

- Convenient online submission

- Thorough peer review

- No space constraints or color figure charges

- Immediate publication on acceptance

- Inclusion in PubMed, CAS, Scopus and Google Scholar

- Research which is freely available for redistribution

Submit your manuscript at www.biomedcentral.com/submit
C Biomed Central 